\title{
A Phenotypic and Genetic Study of Semen Production and Semen Quality Traits Among Young and Adult Cattle Bulls in India
}

Kaustubh Gajanan Bhave ( $\square$ kaustubhbhave89@gmail.com )

BAIF Development Research Foundation https://orcid.org/0000-0001-8252-4622

Thilak Pon Jawahar Koilpillai

TANUVAS: Tamil Nadu Veterinary and Animal Sciences University

Venkataramanan Ragothaman

TANUVAS: Tamil Nadu Veterinary and Animal Sciences University

\section{Shivaji Sontakke}

BAIF Development Research Foundation

\section{Gautami Joshi}

BAIF Development Research Foundation

\section{Rajesh Jadhav}

BAIF Development Research Foundation

Jayant Khadse

BAIF Development Research Foundation

\section{Marimuthu Swaminathan}

BAIF Development Research Foundation

\section{Vincent Ducrocq}

INRAE: Institut National de Recherche pour l'Agriculture l'Alimentation et l'Environnement

\section{Research Article}

Keywords: Semen quality, Semen production, Crossbred cattle, Linear mixed model, Repeatability

Posted Date: February 7th, 2022

DOI: https://doi.org/10.21203/rs.3.rs-1290264/v1

License: (c) (1) This work is licensed under a Creative Commons Attribution 4.0 International License. Read Full License 


\section{Abstract}

Semen characteristics of 97,112 ejaculates from 399 adult bulls of 2 exotic breeds, 2 indigenous breeds and crossbred sub-populations with 50\% and 75\% of exotic inheritance, and of 3,293 ejaculates from 292 test bulls were analysed. The traits considered were: ejaculate volume, sperm concentration, total number of sperms, initial and post-thaw motility, and a theoretical number of doses produced from each given ejaculate. The objective was to measure the semen production potential of different genetic groups of cattle breeds, to identify factors affecting semen production and quality traits, and to assess the correlation between semen characteristics measure on test and adult bulls. A linear mixed model was used to evaluate the effect of different fixed and random effects. For adult bulls, the first ejaculate of a bull on a particular day and longer collection intervals lead to better characteristics for all the parameters but short collection interval with two ejaculate on particular day lead to a larger number of total semen doses produced without hampering semen quality. Repeatability estimates for semen traits were found to be low to moderate. Low to moderate and negative bull correlation was observed between concentration and volume in all the breed groups while the correlations of bull effects of the two motility traits were comparatively large. The moderate to high correlation for all semen traits between their testing and when they are adult highlights the importance of andrology evaluation in predicting future semen production of Al bulls in order to discard the less productive bulls.

\section{Introduction}

Fertility traits in cattle are equally important for males and females. The focus of the dairy industry in India and elsewhere is to get a cow pregnant to maintain the milk production without missing a single favourable oestrus cycle. Unfortunately, male fertility often gets less attention. A male calf reaches sexual maturity when his semen reaches a concentration close to 50 million sperms per $\mathrm{ml}$ with a motility of at least 10 per cent, which is sufficient to achieve pregnancy of a cow (Wolf et al., 1965). However, to get thousands of cows pregnant through artificial insemination using a proven bull to achieve genetic improvement, millions of good quality sperms are required. To ensure whether a bull is able to produce good quality semen, he has to undergo a standard andrology evaluation in order to determine his future.

A better understanding of the impact of different factors such as the number of ejaculates collected on a same day, the interval between collections, the expertise of semen collectors on semen output of exotic, crossbred and indigenous bulls (e.g. of Gir and Sahiwal breeds, two major dairy breeds in India) would be helpful to maximise production of good quality semen doses from young bulls. A better knowledge of parameters such as the correlations between semen traits for purebred, crossbred, and indigenous breeds and the repeatability of these traits would be useful in order to predict the capacity of production of mature bulls, and therefore, to efficiently preselect bulls with sufficient production of good quality semen doses.

The present study analyses and compares semen production of bulls of different cattle breeds: Holstein Friesian (HF), Jersey, Gir and Sahiwal bulls, as well as crossbreds of HF and Jersey with indigenous breeds. Semen was collected under semiarid conditions since 2010 at two frozen semen stations of BAIF (BAIF Development Research Foundation, 2021). BAIF is a large Indian NGO with headquarters at Pune, Maharashtra, India. It provides door to door cattle and buffalo Al service to about 5 million families of small farmers in over 100,000 villages in 13 Indian states.

\section{Materials And Methods}

As the data consisted of many repeated measurements for each bull, a linear mixed repeatability model was used for the analysis of the various traits: a random bull effect was included to account for the between bulls' variability. This effect was supposed to be constant over time for a given bull. Various combinations of the factors described above 
were tested in order to find a proper model. All models included an age effect and a breed effect of the bull. The age effect was included either as a class variable or as a covariate through a quadratic or cubic polynomial. Seasonal effects in on each of the two farms were analysed either as season or month effects within each year. Two-way interactions between breed and age at collection and between semen collector and year of collection were also considered. In total, 9 models combining these different options were analysed using the WOMBAT software (Meyer 2007) to get solutions for fixed and random effects. BIC (Bayesian Information Criterion) and MSE (Mean square error) values for model comparison and significance of fixed effects were obtained using the "ImerTest" package of $R$ software (R Core Team 2021).

Model (1) showed the lowest mean square error against other models for all traits. BIC results for the 9 models were less consistent between traits but differences between best models were not large and for the sake of simplicity, model (1) was selected as the model of choice for all traits. It can be written as:

Yijklmnpqrs $=E i+l j+T k+(B \times A) I m+(C \times Y) n o+(F \times M \times Y) p q o+U r+$ eijklmnopqrs

Where,

Yijklmnpqrs $=$ Semen production trait

$\mathrm{Ei}=$ Fixed effect of the ith order of the ejaculate on a same day $(\mathrm{i}=1,2)$

$\mathrm{lj}=$ Fixed effect of the $j$ th collection interval $(\mathrm{j}=1$ to 3 )

Tk = Fixed effect of the $k$ th collection time ( $k=1$ to 6$)$

$(B \times A) \operatorname{Im}=$ Fixed effect of the Imth breed $\times$ age class interaction $(I=1$ to $6, m=1$ to 12$)$

$(\mathrm{C} \times \mathrm{Y})$ no $=$ Fixed effect of the noth semen collector $\times$ year of collection interaction $(\mathrm{p}=1$ to $12, \mathrm{q}=1$ to 9$)$

$(\mathrm{F} \times \mathrm{M} \times \mathrm{Y})$ pqo $=$ Fixed effect of the pqoth farm $\times$ month $\times$ year of collection interaction $(\mathrm{n}=1$ to 12$)$

Ur $=$ Random effect of the rth bull ( $r=1$ to 399), supposed to follow a normal distribution with mean 0 and variance $\sigma_{b}^{2}$

eijklmnpqrs Random residual associated with each observation, supposed to follow a normal distribution with mean 0 and variance $\sigma_{e}^{2}$

Multi-trait repeatability animal models were used to estimate bull effects (Genetic + permanent environmental effect) among the semen traits for three genetic groups separately viz. 1- Holstein Friesian and their crossbred, 2- Jersey and their crossbred and 3- Gir and Sahiwal. To reflect the potential changes of semen traits with age, 4 periods were defined: the characteristics of the first six ejaculates of every test bull were considered as test bull traits, while the ejaculates of adult bulls were divided in three categories on the basis of age ( 1 to 3 years, 3 to 4 years, and more than 4 years) and treated as a separate trait. A multi-trait repeatability animal model was utilized to estimate bull effects for semen traits of test bulls and adult bulls of different ages.

\section{Results}

\section{Semen production and semen quality traits in adult bulls}


Table 1 displays for each genetic group the number of bulls evaluated and the mean and standard deviation of their semen production and semen quality parameters. The raw means of ejaculate volume (VOL) varied between 5.48 and $6.44 \mathrm{ml}$ with highest volume observed in $\mathrm{HF} 75 \%$ bulls while the lowest volumes were found in Jersey and Sahiwal breeds. Much smaller breed differences were observed for sperm concentration (CONC) with the highest concentration being observed in Jersey bulls. In Sahiwal bulls, both concentration and volume were lower than in other breeds while both traits were relatively high in pure and crossbred HF bulls.

Initial and post thaw motility did not show much variation among the breeds with raw means observed around $75 \%$ and $55 \%$, respectively. Total sperms per ejaculate ranged from 7.0 to 8.5 billion sperms per ejaculate. Higher means for total sperms were observed in HF pure and HF 75\% bulls due to comparatively higher volume and concentration, while the opposite situation was observed in the Sahiwal breed.

\section{Semen production and semen quality traits in test bulls}

As for adult bulls, there was no large variation for concentration, volume, and total sperm traits of test bulls within breeds (Table 2). However, sperm concentration per $\mathrm{ml}$ in HF 50\% and Jersey 50\% were lower compared to the other breed groups. There were substantial differences in motility parameters between all breed groups, to a much larger extent than for adult bulls. For example, the initial motility percentage ranged from 48 to $66 \%$, while post thaw motility ranged from 45 to $52 \%$.

In the case of test bulls, all together 21 bulls were culled due to poor semen quality or morphology (morphology data is not presented). The raw means for semen production and quality parameters of all test bulls and the culled ones are presented in Table 2. It was observed that means for all and culled bulls for sperm concentration, volume and total sperms were not very different except for HF pure and Jersey $50 \%$ crossbreds which showed much lower sperm concentration per $\mathrm{ml}$ and total sperms. The most visible differences among different genetic groups were observed for the motility parameters, except for the HF pure breed bulls for which two culled bulls did not even get post thaw motility results due to poor initial motility.

\section{Factor influencing semen production and quality traits in adult bulls}

The order of the ejaculate on a given day had a significant effect on all semen production traits in adult bulls (Table 3 ). The first ejaculate was considered as reference. Except for post thaw motility, the first ejaculate was superior to the second one collected on the same day. A significant effect of the ejaculate number on a given day was found in all semen traits of test bulls, except for the motility traits (Supplemental table 1) for which the difference among the first and second ejaculates was more pronounced. A large variation in TNSDP ( 88 doses for the second ejaculate compared to the first one) was observed. Similarly, sperm concentration, volume, and total sperms were higher for the first ejaculate than for the second one. A large variation in first and second ejaculates for all semen traits except motility traits observed in test bulls must be interpreted with caution because the second ejaculate for the test bulls was collected only when the bull was not able to produce enough semen in his first attempt. The bull was then allowed to rest before being collected again on the same day.

Collection interval showed a significant effect on all semen traits in adult bulls. Among the three groups of intervals, the first interval group ( 1 to 3 days) was considered as the reference (Table 3 ). As the number of days between collection interval between ejaculates increases, a gradual increment in solutions is observed for all traits except for motility. This is clearly demonstrated with an increase in ejaculate volume and total sperm leading to an increase of +50 and +86 in theoretical number of semen doses at collection intervals of 4 to 6 days and more than 7 days 
respectively against the reference collection interval of 1 to 3 days. Post thaw motility showed a small decrease as the interval between two ejaculates collected on different days increased.

Time of semen collection on a given day significantly $(P<0.01)$ affected the semen traits in adult bulls $($ Table 3$)$ while only volume and TNSDP of test bulls were significantly affected, although the variation along the timeline was not large.

The 4 to 5 -year of age class of HF 75\% bulls was considered as the reference to study the breed $\times$ age class interaction for all semen production traits. The ejaculate volume showed a gradually increasing trend with age in all the breeds except in Gir which declined after a puzzling spike in the 3- to 4 years age interval which is likely due to the very low number (3) of bulls available in this age class (Fig. 1). Total sperms and TNSDP followed a pattern similar to semen volume in all breeds. An opposite trend was observed for sperm concentration (Fig. 2) which gradually decreased with age for several breed categories. However, this decline was small. In the case of motility traits, all the traits showed more or less stable evolution with age except for Jersey bulls with more than $50 \%$ exotic inheritance (bulls with exotic inheritance of 75\%) which showed 3 to $5 \%$ lower values than the other breed groups. We found that about 6 per cent of the ejaculates of Jersey $75 \%$ crossbred bulls were discarded due to low post-thaw motility vs $2 \%$ for the other breeds. However, the opposite scenario was observed for Holstein bulls and their crossbreds: post-thaw motility was larger, with no significant differences between the Holstein crossbreds. Overall,

Sahiwal bulls produced comparatively more $(+34$ to +44$)$ semen doses per ejaculate than the reference value. On the other handthe theoretical semen doses produced by HF $50 \%$ bulls were worse (-102 to -119) until 5 years of age (Supplemental Fig. 1), followed by Jersey $50 \%$ bulls (-81 to -87$)$.

The 2 to 3 -year age class of HF 75\% bulls was considered as the reference for the breed $\times$ age class interaction solutions for all semen production traits of test bulls. Except for post-thaw motility, all the traits were found to be significantly affected by breed $\times$ age class interaction. Sperm concentration of Jersey and HF pure breed bulls showed a stable trend until 3 years of age and later declined gradually. Sperm concentration improved during the period 3-4 year of age in HF 75\% and later declined. On the contrary, semen concentration of Jersey $50 \%$ and HF $50 \%$ improved after age 2-3. The erratic trend of Jersey and HF $50 \%$ crossbred bulls is likely due to the limited number of bulls ( 2 to 5 ) for this age class. Total sperm followed a trend similar to sperm concentration. Unlike sperm concentration, initial motility for the HF50\% was low (the lowest among all breeds). Ejaculate volume increased consistently with age. Postthaw motility remained more or less stable except for the Jersey $75 \%$ bulls for which it declined drastically after 4 years of age, but this represented only 2-3 bulls.

In the present study, both the handling and semen collection were carried out by a same person. The data from semen collector 1 in year 2016 was considered as the reference class to be compared with. The collector $\times$ year of collection interaction was found to have a significant effect $(P<0.01)$ for all semen production parameters. Very small variations due to the collectors were observed for ejaculate volume. On the contrary, sperm concentration per ml was found to be lower for collectors 5 and 6 than the rest of collectors, i.e., the two main collectors of the Jind semen lab. However, all the semen collectors followed similar pattern over the years. The peaks in TNSDP were observed in year 2013, 2015, and 2017, producing higher number of doses per collection (+107 to +165 against references). A similar pattern was also found for total sperms (Supplemental Fig. 2). The collector $\times$ year effects for volume and semen concentration may be relative large on a same year (e.g., with differences between collectors ( 1 to 4 ) of $0.5 \mathrm{ml}$ for volume and $0.15 \times$ $10^{9} / \mathrm{ml}$ for concentration) but they are negatively correlated, leading to variation in TNSDP much smaller within year than between years. Sperm concentration was found to be lower for the $5^{\text {th }}$ and $6^{\text {th }}$ collectors with a difference of 0.2 to 0.3 billion sperms per $\mathrm{ml}$ compared to the other collectors. The performance of collectors 1 to 4 for post thaw motility 
declined consistently from 2010 (+3) to 2017 (-3) and increased sharply in 2018 while collectors 5 and 6 were slightly better than the others, potentially reflecting again a confounding effect between the collectors and the collection farm.

The monthly variations of the traits studied in the two semen stations did not follow a similar trend over the years. There was a large variation $(P<0.01)$ of the month effect observed across traits in the two semen stations during the course of 9 years. Ejaculate volume in the two semen stations follows almost the same pattern (flat line) without much change within years except in 2018, where the volume was $+3 \mathrm{ml}$ higher than the other years. Sperm concentration did not show much variation within year in the Uruli Kanchan semen station, However a peculiar curve was observed in the Jind semen station which peaked in months of May to June and later declined till October and later increased sharply. Similar pattern was also found for total sperms and TNSDP. The year 2018 showed a production of almost +200 TNSDP than the other years (Fig. 3). No particular trend was observed in initial motility over the years. Initial motility had an irregular trend over the years. Post thaw motility in Jind showed almost a straight line overall years with just a decline in motility in 2014, while other years showed improvement after May month. Compared with the Jind semen station, post thaw motility in the Uruli Kanchan semen station showed more variation within years.

\section{Repeatability and bull correlation estimates for semen production and quality traits in adult bulls}

The bull effect in model (1) represents the sum of the genetic effect of the bull and of its permanent environment effect, or in other words, the specific characteristics of the bull which influence the semen production or semen quality phenotypes, after correction for all environmental effects. The repeatability of the bull effect is the proportion of the total variance which is due to the bull effect. Table 4 and Supplemental tables 2 and 3 present this repeatability (on the diagonal) as well as the phenotypic correlations (below the diagonal) and the bull effect correlations (above the diagonal) for HF and HF crossbreds, Jersey and Jersey crossbreds, and Gir and Sahiwal respectively. Only the first ejaculate was included in the analysis for a given day, to avoid the specification of a particular residual correlation structure between the first and the second ejaculate of a same animal on a given day.

The repeatability estimates of ejaculate volume, sperm concentration and TNSDP in all genetic groups were relatively moderate (ranging from 0.32 to 0.45 ) while motility traits had a low repeatability in HF and their crossbred and indigenous genetic group bulls. In contrast, moderate repeatability estimates for motility traits were observed in the Jersey and their crossbred bulls ( 0.33 and 0.37 for initial and post thaw motility, respectively).

Low to moderate and negative bull correlations were observed between concentration and volume in all three breed combinations. Correlations of bull effects of the two motility traits were large (0.58 to 0.89). The estimates of the bull effect correlations between TNSDP and either concentration or volume were moderate to high and of the same order of magnitude ( 0.36 to 0.70$)$. The correlations between TNSDP with motility traits were similar or slightly lower ( 0.34 to 0.55 for exotic breeds and crossbreds, about 0.24 for indigenous breeds but with a large standard error).

\section{Bull correlation estimates for semen production and quality traits among adult and test bulls}

These analyses were performed only on (purebred and crossbred) Holstein and Jersey bulls because test bull records were not available for indigenous bulls. A high correlation of bull effects was observed between the characteristics of the first 6 ejaculates of test bulls and at 1 to 3 years of age for adult bulls of HF and their crossbreds for sperm concentration, volume, total sperms, and especially for TNSDP (0.82). The correlation observed for motility traits (0.59) was not as high but still quite large (Table 5). As expected, most of these correlations decreased with the subsequent age groups of adult bulls for all the traits. Bull correlation for post thaw motility increased as the age progressed, while it remained stable for initial motility, but the standard errors of these correlations were very large. The bull effect correlations among the adult bulls remained high. In Jersey and their crossbreds, high bull effect correlations were also 
observed for sperm concentration and motility traits. Bull correlations for motility traits between test bulls and all the categories of adult bulls remained high and stable (Supplemental table 4).

\section{Discussion}

On the basis of raw means in terms of total sperm and TNSDP, it was observed that HF and HF 75\% performed comparatively better than the rest of the breed groups while among indigenous breeds, Gir bulls were found to be better than Sahiwal ones. Earlier study on body weight reported that the larger bulls were better in semen production than smaller bulls (Asad et al., 2004). This is also the case in the present study where Gir, HF and their crossbreds performed better than smaller size breeds or breed groups such as Sahiwal, Jersey and their crossbreds.

The superiority of first ejaculates to second found in present study leads to the production more semen doses when ejaculates collected on same day,. The motivation behind the collection of two ejaculates on a same day in adult bulls is to increase daily sperm output without affecting the quality of semen. The higher characteristics of the first ejaculate over the second ones were also reported by Taylor et al. (1985) in HF pure, Bhakat et al. (2011) in Sahiwal, and Gopinathan (2014) in HF crossbred for volume, concentration, total sperm and initial motility. These differences are the direct consequence of the two ejaculates being collected within 15 to 30 minutes of interval on a same day.

The significant increment was in solutions of all semen traits except for motility traits observed due to comparatively bigger collection intervals than smaller ones. However to achieve profitability of semen station, an Al frozen semen station must target the smaller collection intervals. The frozen semen station has to manage a high demand of quality semen for the field. In such a commercial set up, continuous provision of quality semen is incompatible with long intervals between collection days. This can be illustrated through simple calculation. A bull produces on average (roughly) 400 and 250 semen doses from his first and second ejaculates on a given day with 20 million sperms per $0.25 \mathrm{ml}$ of semen dose. This way, a 2-day interval between collection days yields 1650 semen doses per week. Similarly, 4 and 7-day intervals respectively yield 1100 and 550 semen doses per week respectively. From these calculations, it appears that 2 to 4 days of collection interval increases profitability while keeping good semen quality.

The solutions for the semen traits decreased slightly as the time progressed on given collection day. The gradual change in semen traits can be explained by the rise in atmospheric temperature which may affect testicular temperature. This has been observed in some studies (Taylor et al., 1985 for semen volume and total sperms and (Fuerst-Waltl et al., 2006) for mass activity and initial motility). Maintaining the testicular temperature lower than body temperature is essential for the production of fertile spermatozoa. Fuerst-Waltl et al. (2006) reported a change in sperm concentration due to heat stress during the sensitive stages of spermatogenesis and epididymis maturation. The current study did not include ambient temperature at collection time. This should be considered in future studies.

The increase of the ejaculate volume and total sperms with age at collection observed in our study could be due to the increase in the hypothalamus - pituitary gland activity and the development of the testes and accessory sexual glands after sexual maturity (Almquist, 1978). The trends showed in the present study for ejaculate volume and total sperms were similar to those reported by Mathevon et al. (1998a), Brito et al. (2002), and Murphy et al. (2018).

The opposite trends found between sperm concentration and ejaculate volume over the age at collection are certainly due to the negative within-bull correlation between the two traits. The slightly irregular patterns observed in Jersey $50 \%$ and Gir showed can be at least partly explained by the limited number of bulls. A decrease in motility in Jersey bulls with high exotic inheritance was in accordance with studies of Mathew et al. (1982) and Sagdeo et al. (1990) who also reported a decrease in post-thaw motility with increased exotic contribution. Poor performance of HF50\% in terms of theoretical semen doses produced was also reported by Tripathi et al. (2015). They observed that proportion of Sertoli

Page $7 / 17$ 
cells in crossbred bulls (Karan Fries - a cross between pure HF and Tharparkar indigenous cattle breed) were lower than the purebred HF and Tharparkar. The fertile spermatozoa are a result of proper functioning of germ cells and Sertoli cells. These germ cells maintained by a single Sertoli cell illustrate the functional efficiency of this cell, directly correlated with spermatogenic activity. They are good indicator of daily spermatozoa production (Franca and Godinho, 2003). The decreased semen production in HF and Jersey crossbreds may also be the result of a lower proportion of Sertoli cells as compared with indigenous and pure exotic bulls.

Among test bulls, the semen characteristics especially initial motility of HF $50 \%$ bulls were the worst, followed by Jersey $75 \%$ bulls which prolonged the time taken to pass andrology assessment tests. On average, HF $50 \%$ bulls took 169 days to clear the andrology assessment test, the longest period among all breed groups, while pure HF test bulls took on average 63 days, followed by HF $75 \%$ test bulls (70 days). Indeed, 24 HF 50\% test bulls out of 37 (64\%) needed more than 60 days to complete the test, and 20 of them (54\%) required more than 100 days. Other studies reported poor seminal profile of crossbred bulls and poor libido in indigenous cattle (e.g., Mukhopadhyay et al., 2010, Khatun et al., 2013). This leads to comparatively longer time for the crossbred and indigenous bulls to pass the assessment criteria. The age of induction of test bulls for assessment tests is also very variable: 12 out of 90 Jersey bulls and their crossbreds (13\%) and 38 out of 202 bulls of HF and their crossbreds (18\%) were inducted after 3 years of age. This could be due to slow growth rate of bulls, delayed arrival in test station from the field or due to low demand of semen from a particular breed composition.

Bull semen collectors have a large impact on semen production of bulls (Fuerst-Waltl et al. 2006) and daily semen collection practices such as the way of restraining, and the sexual preparation are strongly dependent on the collector. The importance of the effect of the semen collector was also reported by Dominguez et al. (1994) for ejaculate volume, by Komisrud and Berg (1996), for volume and post-thaw motility by Mathevon et al. (1998a) for concentration, for volume and total sperms per ejaculate, and by Fuerst-Waltl et al. (2006) for concentration, volume, total sperm and initial motility.

The increased sperm concentration, total sperm and subsequently number of theoretical number of doses produced during summer months (March to May) and declined from June month onwards till October can be explained on the basis of the spermatogenesis process which takes 65 days on average (Dorst, 1991). More favourable climatic conditions during the winter and their subsequent effect on sensitive stages of spermatogenesis resulted in better sperm concentration, ultimately leading to higher numbers of semen doses produced. In contrast, the hot climate in summer resulted in lower semen output and fewer doses produced during the monsoon season.

Repeatability estimates for semen production and quality traits across different genetic groups were found ranged from low to moderate. There are very few studies reported high repeatability estimates in motility traits despite of using similar method of motility evaluation, ranged from 0.40 to 0.72 (Goinathan, 2014 (initial motility); Atagi et al., 2017 and Sarakula et al., 2018) while Mathevon et al. (1998a) reported higher estimates for volume and concentration. The difference in the estimates of repeatability among these studies are probably due to different ages, breeds, and model of analysis.

Choosing, raising, training and maintaining an Al bull a long and costly process. Whatever its origin, poor production and early culling due to poor or declining semen production may be a financially very detrimental decision. The last part of the analyses aimed at verifying whether the bull characteristics measured early in life, based on the first 6 ejaculates, are representative of future semen production.

The high bull correlations for all semen traits between their test period and when they are adult highlights the benefit of early andrology evaluation in predicting future semen production of Al bulls. These results are consistent with those of 
Humblot et al. (1993) and Mathevon et al. (1998b) who found similar correlations in Normande and French Montbéliard bulls.

Our results illustrate that the early culling of inferior young bulls, based on classical quantitative and qualitative semen characteristics at the end of the test period in station is one way to increase semen production of proven bulls, as long as the cost in terms of loss in genetic gain on the main traits of interest is not too large. Moderate to large bull correlation estimates between TNSDP with other semen traits illustrate the potential role of TNSDP as a trait nicely summarizing the semen production characteristics of a bull.

In conclusion, we propose a synthetic trait - the theoretical (standardized) number of doses produced from each ejaculate to be considered in addition to the usual traits of semen analysis. Whatever the breed or breed cross considered, we showed that it is economically beneficial and physiologically sound to collect 2 ejaculates on a same day and at short collection intervals (e.g., 1 to 3 days) as it can increase the total semen output by a 2-to 3-fold increment. Pure Holstein and high grade (75\%) Holstein crossbred bulls produce more semen (>+10\%) than Jersey and Gir bulls, and about 15\% more than Jersey crossbreds and Sahiwal. Management factors (time of collection and number of ejaculates collected on a same day, interval between collections, age of the bull, month and year, expertise of the collector, etc.) influence substantially semen output and semen quality. However, our results showed that there is a large individual component - the bull effect - which influences semen output and semen quality during the whole life of the animal. The repeatability estimates of the bull effect gives the higher limit of the heritability for semen production traits, if genetic selection of the best bulls is desired.

Semen production and quality of the first 6 ejaculates was shown to reflect future semen production relatively well. Therefore, it can be used to predict future production and discard early the less productive bulls.

An unanswered question is the cause of the lower production of crossbred bulls, especially the $50 \%$ Bos taurus-Bos indicus ones. Besides reasons linked to the combination of the two sub-species which may explain a lower male fertility, the age when the crossbred bulls are trained to produce their first ejaculates (age at induction) should be considered: With the development of genomic selection and its associated short generation interval, purebred Holstein and Jersey bulls are nowadays often producing semen when they are about one year old (vs more than 3-year old for some of the crossbred bulls considered here).

\section{Declarations}

\section{Acknowledgments}

The authors thank colleagues of frozen semen station of BAIF Development Research Foundation for permission to utilize their data and the constant support during the study. The authors acknowledge the Department of Animal Genetics and Breeding, Madras Veterinary College, Tamil Nadu Veterinary and Animal Sciences University (TANUVAS), Chennai for the facilities provided.

\section{Ethical standards}

The manuscript does not contain clinical studies or patient data.

\section{Funding}

This study did not receive any funding.

\section{Conflict of Interest Statement}


The authors declare that they have no conflict of interest.

\section{Data availability}

Not applicable.

\section{Code availability}

Not applicable.

\section{Authors' Contributions}

All listed authors have made substantial contributions to the research design, or the acquisition, analysis, or interpretation of data, and drafting the manuscript or revising it critically. All authors have approved the submitted version.

\section{Ethical approval}

Not applicable

\section{Consent to participate}

Not applicable

\section{Consent for publication}

Not applicable

\section{References}

1. Almquist, J.O., 1978. Bull semen collection procedures to maximize output of sperm. Proc. of 7th Tech. Conf. on Artificial Insemination and Reproduction. NAAB, 33--36.

2. Asad, L., Hussain, S.S., Rahman, M.G.M., Khandoker, M.A.M.Y., Hossain, M.E. and Rahman, M.Z, 2004. Genetic and non-genetic factors affecting the semen quality of bulls. Pakistan Journal of Biological Sciences, 7, 1903-1907.

3. Atagi, Y., Onogi, A., Kinukawa, M., Ogino, A., Kurogi, K., Uchiyama, K., Yasumori, T., Adachi, K., Togashi, K. and Iwata, H., 2017. Genetic analysis of semen production traits of Japanese Black and Holstein bulls: genome-wide markerbased estimation of genetic parameters and environmental effect trends. Journal of Animal Sciences, 95(5), 1900$-1912$.

4. BAIF Development Research Foundation. 2021. http://www.baif.org.in/. Accessed 18 July, 2021.

5. Bhakat, M., Mohanty, T.K., Raina, V.S., Gupta, A.K., Khan, H.M., Mahapattra, R.K. and Sarkar, M., 2011. Effect of age and season on semen quality parameters in Sahiwal bulls. Tropical Animal Health Production 43(6), 1161-1168.

6. Bhave, K., Koilpillai, T. P. J., Ragothaman, V., Sontakke, S., Joshi, G., \& Ducrocq, V. (2020). Semen production and semen quality of indigenous buffalo breeds under hot semiarid climatic conditions in India. Tropical Animal Health and Production, 52, 2529-2539.

7. Brito, L.F.C., A.E.D.F. Silva, L.H. Rodrigues, F.V. Vieira, Deragon L.A.G. and J.P. Kastelic, 2002. Effect of age and genetic group on characteristics of the scrotum, testes and testicular vascular cones, and on sperm production and semen quality in Al bulls in Brazil. Theriogenology, 58(6), 1175--1186. 
8. Department of Animal Husbandry, 2019. Minimum Standards for Production of bovine frozen semen. Department of Animal Husbandry, Dairying and Fisheries, Ministry of Agriculture, Government of India. http://dahd.nic.in. (Accessed 18th May 2021)

9. Dominguez, J.C., Alegre, B., Molero, R., Carbajo, M., Anel, L. and Boixo, J.C., 1994. Effect of management on semen quality of Brown Swiss Al bulls. Veterinary Medicine 11, 332-340.

10. Dorst, J., 1991. Morphologie des Geschlechtssystems. In: Busch, W., Lohle, K., Peter, W. (Eds.), K “ unstliche Besamung “ bei Nutztieren. Gustav Fischer Jena, Stuttgart, 169-208.

11. Franca, L.R. and Godinho, C.L., 2003. Testis morphometry, seminiferous epithelium cycle length, and daily sperm production in domestic cats (Felis catus). Biological Reproduction, 68(5), 1554-1561.

12. Fuerst-Waltl, B, Schwarzenbacher, H., Perner C. and Solkner, J. 2006. Effects of age and environmental factors on semen production and semen quality of Austrian Simmental bulls. Animal Reproduction Science 95, 27--37.

13. Gopinathan, A., 2014. Genetic studies on semen production in Jersey crossbred and Holstein Friesian crossbred bulls. Ph.D. dissertation. Tamil Nadu Veterinary and Animal Sciences University, Chennai, Tamil Nadu, India.

14. Humblot, P., Ducrocq, V. and Nemeth, C., 1993 Relationship between semen characteristics of young and adult bulls in the Normande breed. Livestock Production Scince, 35, 265--281.

15. Khatun M., Kaur, S. and Kanchan C.S., 2013. Subfertility Problems Leading to Disposal of Breeding Bulls. AsianAust. Journal of Animal Science 26(3), 303-308.

16. Komisrud, E. and Berg, A.K., 1996. The influence of duration of sexual preparation on bovine semen characteristics and fertility rates. Reproduction in Domestic Animal 31(2), 369-371.

17. Mathevon, M., Buhr, M.M. and Dekkers, J.C. 1998a. Environmental, management, and genetic factors affecting semen production in Holstein bulls. Journal of Dairy Science, 81, 3321--3330.

18. Mathevon, M., Dekkers J.C.M. and Buhr M.M., 1998b. Environmental, management and genetic factors affecting semen production in French Montbéliard bulls. Livestock Production Science, 55, 65-77

19. Mathew, A., Joseph, P.J. and Jose, T. K., 1982. Semen characteristics of purebred and crossbred bulls. Indian Veterinary Journal 59, 364-367.

20. Meyer, K., 2007. WOMBAT- A tool for mixed model analyses in quantitative genetics by restricted maximum likelihood (REML). J Zhejiang Univ Sci B. 8(11), 815--821.

21. Mukhopadhyay, C.S., A.K. Gupta, B.R. Yadav, K. Khate, V.S. Raina, Mohanty T.K. and P.P. Dubey, 2010. Subfertility in males: an important cause of bull disposal in bovines. Asian- Australasian Journal of Animal Sciences, 23(4), 450-455 .

22. Murphy, E.M., Kelly, A.K., O’Meara, C., Eivers, B., Lonergan, P. and Fair, S., 2018. Influence of bull age, ejaculate number, and season of collection on semen production and sperm motility parameters in Holstein Friesian bulls in a commercial artificial insemination centre. Animal Science Journal, 96(6), 2408-2418.

23. R Core Team, 2021. R: A language and environment for statistical computing. R Foundation for Statistical Computing, Vienna, Austria. Version: 4.1.0.). https://www.R-project.org/. (Accessed 21st July 2021).

24. Sagdeo, L.R., Chitnis, A.B., Deshmukh, S.N. and Kaikini, A.S., 1990. Studies on semen freezability of pure Jersey and crossbred bulls with varying levels of exotic inheritance. Indian Journal of Animal Reproduction, 11(2), 79-84.

25. Sarakula, M, Mauricio A.E., Koonawootrittrirona, S., Suwanasopeea, T. and Jattawaa, D., 2018. Genetic parameters, predictions, and rankings for semen production traits in a Thailand multi-breed dairy population using genomicpolygenic and polygenic models. Animal Reproduction Science, 195, 71-79.

26. Taylor, J.F., Bean, B., Marshall, C.E. and Sullivan, J.J., 1985. Genetic and environmental components of semen production traits of artificial insemination Holstein bulls. Journal of Dairy Science, 68, 2703-2722. 
27. Tripathi, U.K., Chhillar, S., Kumaresan, A., Aslam, M.M., Rajak, S.K., Nayak, S., Manimaran, A., Mohanty, T.K. and Yadav, S., 2015. Morphometric evaluation of seminiferous tubule and proportionate numerical analysis of Sertoli and spermatogenic cells indicate differences between crossbred and purebred bulls. Veterinary World, 8(5), 645-650 .

28. Wolf, F.R., Almquist, J.O. and Hale, E.B., 1965. Prepuberal behavior and puberal characteristics of beef bulls on high nutrient allowance. Journal of Animal Sciences, 24, 761-765.

\section{Tables}

Table 1. Number of observations, mean, and standard deviation of semen production traits, per breed of adult bulls

\begin{tabular}{|c|c|c|c|c|c|c|c|c|}
\hline Breed & $\begin{array}{l}\text { No. } \\
\text { of } \\
\text { bulls }\end{array}$ & $\begin{array}{l}\text { No. of } \\
\text { records }\end{array}$ & $\begin{array}{l}\text { CONC } \\
\left(10^{9} / \mathrm{ml}\right)\end{array}$ & $\begin{array}{l}\text { VOL } \\
(\mathrm{ml})\end{array}$ & $\begin{array}{l}\text { TS } \\
\left(10^{9} / \text { ejaculate }\right)\end{array}$ & $\begin{array}{l}\mathrm{IM} \\
(\%)\end{array}$ & $\begin{array}{l}\text { PTM } \\
(\%)\end{array}$ & $\begin{array}{l}\text { TNSDP } \\
\text { (Semen } \\
\text { doses) }\end{array}$ \\
\hline HF & 94 & $\begin{array}{l}22,149- \\
24,112\end{array}$ & $1.36 \pm 0.53$ & $6.29 \pm 2.05$ & $8.54 \pm 4.17$ & $76.1 \pm 9.7$ & $55.5 \pm 4.2$ & $490.0 \pm 220.3$ \\
\hline HF 75\% & 100 & $\begin{array}{l}24,167- \\
27,570\end{array}$ & $1.31 \pm 0.52$ & $6.44 \pm 2.17$ & $8.31 \pm 4.05$ & $75.7 \pm 11.0$ & $55.3 \pm 4.3$ & $485.3 \pm 215.7$ \\
\hline HF 50\% & 28 & $\begin{array}{l}3,639- \\
4,603\end{array}$ & $1.25 \pm 0.55$ & $6.20 \pm 2.32$ & $7.69 \pm 4.29$ & $71.5 \pm 14.4$ & $55.2 \pm 5.8$ & $445.0 \pm 224.2$ \\
\hline Jersey & 73 & $\begin{array}{l}15,609- \\
17,084\end{array}$ & $1.43 \pm 0.51$ & $5.48 \pm 2.05$ & $7.75 \pm 3.72$ & $76.2 \pm 8.95$ & $54.7 \pm 7.1$ & $434.7 \pm 208.3$ \\
\hline $\begin{array}{l}\text { Jersey } \\
75 \%\end{array}$ & 24 & $\begin{array}{l}4,251- \\
5,058\end{array}$ & $1.25 \pm 0.52$ & $5.98 \pm 1.94$ & $7.42 \pm 3.81$ & $74.0 \pm 12.4$ & $53.6 \pm 8.1$ & $421.8 \pm 206.9$ \\
\hline $\begin{array}{l}\text { Jersey } \\
50 \%\end{array}$ & 23 & $\begin{array}{l}5,051- \\
5,708\end{array}$ & $1.28 \pm 0.59$ & $5.67 \pm 2.01$ & $7.25 \pm 4.20$ & $75.4 \pm 11.8$ & $55.7 \pm 5.4$ & $422.4 \pm 230.9$ \\
\hline Sahiwal & 38 & $\begin{array}{l}9,497- \\
10,399\end{array}$ & $1.27 \pm 0.66$ & $5.48 \pm 1.90$ & $7.05 \pm 4.29$ & $75.7 \pm 9.3$ & $56.2 \pm 3.0$ & $416.2 \pm 230.9$ \\
\hline Gir & 19 & $\begin{array}{l}1,735- \\
2,006\end{array}$ & $1.28 \pm 0.63$ & $5.61 \pm 2.05$ & $7.37 \pm 4.72$ & $74.7 \pm 10.4$ & $55.6 \pm 4.0$ & $437.0 \pm 255.0$ \\
\hline
\end{tabular}

CONC: Sperm concentration $\left(10^{9} / \mathrm{ml}\right)$, VOL: Ejaculate volume $(\mathrm{ml}), \mathrm{TS}$ : Total sperms ( $10^{9} /$ ejaculate), IM: Initial motility (\%), PTM: Post thaw motility (\%), TNSDP: Theoretical number of semen doses.

Table 2. Number of observations, mean, and standard deviation of semen production traits, per breed of test bulls 


\begin{tabular}{|c|c|c|c|c|c|c|c|c|}
\hline Breed & $\begin{array}{l}\text { No. } \\
\text { of } \\
\text { bulls }\end{array}$ & $\begin{array}{l}\text { No. of } \\
\text { records }\end{array}$ & $\begin{array}{l}\text { CONC } \\
\left(10^{9} / \mathrm{ml}\right)\end{array}$ & $\begin{array}{l}\text { VOL } \\
(\mathrm{ml})\end{array}$ & $\begin{array}{l}\text { TS } \\
\left(10^{9} /\right. \\
\text { ejaculate })\end{array}$ & $\begin{array}{l}\text { IM } \\
(\%)\end{array}$ & $\begin{array}{l}\text { PTM } \\
\text { (\%) }\end{array}$ & $\begin{array}{l}\text { TNSDP } \\
\text { (Semen } \\
\text { doses) }\end{array}$ \\
\hline
\end{tabular}

\begin{tabular}{lllllllll}
\hline HF & 77 & $541-$ & $1.34 \pm 0.66$ & $3.98 \pm 2.26$ & $5.41 \pm 4.43$ & $66.0 \pm 20.4$ & $48.0 \pm 13.9$ & $273.7 \pm 213.6$ \\
\hline (culled) & 2 & & $0.28 \pm 0.65$ & $5.26 \pm 2.38$ & $1.71 \pm 3.91$ & $31.5 \pm 25.7$ & - & - \\
\hline $\mathbf{H F}$ & 88 & $579-$ & $1.25 \pm 0.59$ & $4.39 \pm 2.92$ & $5.63 \pm 4.93$ & $59.0 \pm 26.0$ & $49.92 \pm 12.8$ & $319.7 \pm 253.9$ \\
$\mathbf{7 5 \%}$ & & 963 & & & & & & \\
\hline (culled) & 5 & & $1.12 \pm 0.69$ & $4.80 \pm 2.51$ & $4.90 \pm 4.41$ & $29.3 \pm 23.5$ & $32.30 \pm 16.78$ & $41.7 \pm 31.0$ \\
\hline $\mathbf{H F}$ & 37 & $296-$ & $1.07 \pm 0.64$ & $4.94 \pm 2.45$ & $5.27 \pm 4.19$ & $48.2 \pm 25.0$ & $45.00 \pm 14.32$ & $263.7 \pm 208.9$ \\
$\mathbf{5 0 \%}$ & & 744 & & & & & & \\
\hline (culled) & 8 & & $0.89 \pm 0.58$ & $5.74 \pm 2.52$ & $5.32 \pm 4.42$ & $30.0 \pm 24.3$ & $38.75 \pm 12.01$ & $241.7 \pm 143.0$ \\
\hline Jersey & 55 & $431-$ & $1.71 \pm 0.56$ & $3.33 \pm 1.91$ & $5.67 \pm 3.82$ & $65.0 \pm 22.2$ & $46.72 \pm 14.02$ & $247.9 \pm 191.0$ \\
\hline (culled) & 3 & & $1.66 \pm 0.64$ & $3.68 \pm 2.3$ & $6.11 \pm 3.86$ & $50.6 \pm 25.5$ & $27.50 \pm 15.39$ & $178.4 \pm 115.0$ \\
\hline Jersey & 19 & $109-$ & $1.34 \pm 0.54$ & $3.68 \pm 2.90$ & $4.50 \pm 3.98$ & $57.1 \pm 24.5$ & $47.43 \pm 15.40$ & $237.4 \pm 223.3$ \\
$\mathbf{7 5 \%}$ & & 209 & & & & & & \\
\hline (culled) & 1 & & $1.01 \pm 0.32$ & $8.01 \pm 2.7$ & $8.11 \pm 3.91$ & $44.3 \pm 18.7$ & $35.09 \pm 17.32$ & $216.5 \pm 142.6$ \\
\hline Jersey & 16 & $105-$ & $1.03 \pm 0.58$ & $4.24 \pm 2.74$ & $4.37 \pm 3.22$ & $57.5 \pm 22.9$ & $52.45 \pm 9.24$ & $289.3 \pm 187.5$ \\
$\mathbf{5 0 \%}$ & & 200 & & & & & & \\
\hline (culled) & 2 & & $0.56 \pm 0.61$ & $4.78 \pm 2.51$ & $2.78 \pm 4.46$ & $35.0 \pm 23.4$ & $25.01 \pm 16.32$ & $155.9 \pm 136.5$ \\
\hline
\end{tabular}

CONC: Sperm concentration $\left(10^{9} / \mathrm{ml}\right)$, VOL: Ejaculate volume $(\mathrm{ml})$, TS: Total sperms ( $10^{9} /$ ejaculate), IM: Initial motility (\%), PTM: Post thaw motility (\%), TNSDP: Theoretical number of semen doses.

Table 3. Fixed effects of semen production and semen quality traits in adult bulls 


\begin{tabular}{|c|c|c|c|c|c|c|}
\hline $\begin{array}{l}\text { No. } \\
\text { recs }\end{array}$ & $\begin{array}{l}\text { CONC } \\
\left(10^{9} / \mathrm{ml}\right)\end{array}$ & $\begin{array}{l}\text { VOL } \\
(\mathrm{ml})\end{array}$ & $\begin{array}{l}\text { TS } \\
\text { (10\%/ejaculate) }\end{array}$ & $\begin{array}{l}\mathrm{IM} \\
(\%)\end{array}$ & $\begin{array}{l}\text { PTM } \\
\text { (\%) }\end{array}$ & $\begin{array}{l}\text { TNSDP } \\
\text { (Semen } \\
\text { doses) }\end{array}$ \\
\hline Ejaculate no & $\star *$ & $\star *$ & $\star *$ & $\star \star$ & $\star \star$ & $\star *$ \\
\hline 1 & $0^{*}$ & $0^{*}$ & $0 *$ & $0 *$ & $0 *$ & $0 *$ \\
\hline 2 & $-0.27 \pm 0.12$ & $-0.82 \pm 0.51$ & $-1.62 \pm 0.85$ & $-0.85 \pm 2.35$ & $0.88 \pm 1.25$ & $-181.33 \pm 48.18$ \\
\hline Collection interval & ** & ** & ** & ** & ** & ** \\
\hline $\begin{array}{l}1 \text { to } 3 \\
\text { days }\end{array}$ & $0 *$ & $0 *$ & $0 *$ & $0 *$ & $0 *$ & $0 *$ \\
\hline $\begin{array}{l}4 \text { to } 6 \\
\text { days }\end{array}$ & $0.09 \pm 0.03$ & $0.27 \pm 0.01$ & $0.95 \pm 0.02$ & $0.27 \pm 0.06$ & $-0.14 \pm 0.03$ & $50.01 \pm 1.32$ \\
\hline$\geq 7$ days & $0.14 \pm 0.05$ & $0.70 \pm 0.02$ & $1.82 \pm 0.04$ & $-0.33 \pm 0.13$ & $-0.73 \pm 0.07$ & $86.97 \pm 2.64$ \\
\hline Time of collection & ** & ** & ** & ** & * & ** \\
\hline$\leq 6 \mathrm{am}$ & $0 *$ & $0 *$ & $0 *$ & $0 *$ & $0 *$ & $0 *$ \\
\hline 6 to $\leq 7$ & $-0.01 \pm 0.014$ & $0.04 \pm 0.053$ & $0.03 \pm 0.10$ & $0.60 \pm 0.29$ & $-0.14 \pm 0.15$ & $4.73 \pm 5.78$ \\
\hline 7 to $\leq 8$ & $-0.02 \pm 0.014$ & $0.05 \pm 0.053$ & $0.10 \pm 0.10$ & $0.49 \pm 0.30$ & $-0.25 \pm 0.15$ & $8.41 \pm 5.88$ \\
\hline 8 to $\leq 9$ & $-0.04 \pm 0.014$ & $0.02 \pm 0.053$ & $-0.06 \pm 0.10$ & $0.29 \pm 0.30$ & $-0.16 \pm 0.15$ & $1.45 \pm 5.93$ \\
\hline 9 to $\leq 10$ & $-0.04 \pm 0.014$ & $0.02 \pm 0.054$ & $-0.07 \pm 0.10$ & $0.20 \pm 0.31$ & $-0.13 \pm 0.16$ & $4.88 \pm 6.04$ \\
\hline$>10 \mathrm{am}$ & $-0.05 \pm 0.015$ & $-0.03 \pm 0.06$ & $-0.19 \pm 0.10$ & $0.19 \pm 0.32$ & $-0.32 \pm 0.16$ & $3.23 \pm 6.24$ \\
\hline
\end{tabular}

**indicates $\mathrm{P}<0.01$ significance level; 0 *: Reference value for class variables; CONC: Sperm concentration $\left(10^{9} / \mathrm{ml}\right)$, VOL: Ejaculate volume $(\mathrm{ml}), \mathrm{TS}$ : Total sperms (10\% /ejaculate), IM: Initial motility (\%), PTM: Post thaw motility (\%), TNSDP: Theoretical number of semen doses.

Table 4. Repeatability of bull effect, phenotypic correlations and bull effect correlations in HF and HF crossbred bulls

\begin{tabular}{llllll} 
Traits & CONC & $\begin{array}{l}\text { VOL } \\
(\mathrm{ml})\end{array}$ & $\begin{array}{l}\text { IM } \\
(\%)\end{array}$ & $\begin{array}{l}\text { PTM } \\
(\%)\end{array}$ & $\begin{array}{l}\text { TNSDP } \\
\text { (Semen doses) }\end{array}$ \\
\hline CONC & $\mathbf{0 . 4 1} \pm \mathbf{0 . 0 2}$ & $-0.25 \pm 0.07$ & $0.23 \pm 0.07$ & $0.15 \pm 0.07$ & $0.67 \pm 0.04$ \\
\hline VOL & $-0.15 \pm 0.03$ & $\mathbf{0 . 3 6} \pm \mathbf{0 . 0 3}$ & $0.15 \pm 0.07$ & $0.11 \pm 0.07$ & $0.54 \pm 0.05$ \\
\hline IM & $0.13 \pm 0.02$ & $0.06 \pm 0.02$ & $\mathbf{0 . 2 9} \pm \mathbf{0 . 0 2}$ & $0.89 \pm 0.02$ & $0.43 \pm 0.06$ \\
\hline PTM & $0.03 \pm 0.02$ & $0.03 \pm 0.02$ & $0.22 \pm 0.02$ & $\mathbf{0 . 1 9} \pm \mathbf{0 . 0 2}$ & $0.34 \pm 0.07$ \\
\hline TNSDP & $0.33 \pm 0.02$ & $0.25 \pm 0.02$ & $0.16 \pm 0.02$ & $0.20 \pm 0.02$ & $\mathbf{0 . 3 4} \pm \mathbf{0 . 0 2}$
\end{tabular}

Correlation between phenotypes (below the diagonal) and Bull effects (above the diagonal, Repeatability of bull effect: (on the diagonal); CONC: Sperm concentration $\left(10^{9} / \mathrm{ml}\right)$, VOL: Ejaculate volume $(\mathrm{ml})$, TS: Total sperms ( $10^{9} /$ ejaculate), IM: Initial motility (\%), PTM: Post thaw motility (\%), TNSDP: Theoretical number of semen doses. 
Table 5. Bull effect correlations between test bulls and adult bulls in HF and HF crossbred bulls

\begin{tabular}{lllllll} 
TRAITS & \multicolumn{7}{l}{ HF and HF crossbreds } & & & \\
\cline { 2 - 7 } & CONC & VOL & TS & IM & PTM & TNSDP \\
\hline Test bulls - Adult 1 & $0.78 \pm 0.05$ & $0.77 \pm 0.05$ & $0.75 \pm 0.06$ & $0.59 \pm 0.08$ & $0.59 \pm 0.28$ & $0.82 \pm 0.07$ \\
\hline Test bulls - Adult 2 & $0.65 \pm 0.05$ & $0.73 \pm 0.06$ & $0.62 \pm 0.07$ & $0.65 \pm 0.06$ & $0.81 \pm 0.30$ & $0.63 \pm 0.08$ \\
\hline Test bulls - Adult 3 & $0.57 \pm 0.07$ & $0.65 \pm 0.07$ & $0.54 \pm 0.08$ & $0.60 \pm 0.07$ & $0.82 \pm 0.30$ & $0.51 \pm 0.10$ \\
\hline Adult 1 - Adult 2 & $0.91 \pm 0.02$ & $0.92 \pm 0.02$ & $0.92 \pm 0.02$ & $0.95 \pm 0.01$ & $0.92 \pm 0.03$ & $0.91 \pm 0.02$ \\
\hline Adult 1 - Adult 3 & $0.82 \pm 0.03$ & $0.80 \pm 0.04$ & $0.80 \pm 0.04$ & $0.82 \pm 0.04$ & $0.80 \pm 0.05$ & $0.79 \pm 0.03$ \\
\hline Adult 2 - Adult 3 & $0.92 \pm 0.01$ & $0.88 \pm 0.02$ & $0.90 \pm 0.02$ & $0.92 \pm 0.02$ & $0.91 \pm 0.02$ & $0.91 \pm 0.02$
\end{tabular}

Test bulls: first 6 ejaculates Adult 1: 1 to 3 years of age, Adult 2: 3 to 4 years of age, Adult 3: 4 to 5 years of age;

CONC: Sperm concentration $\left(10^{9} / \mathrm{ml}\right)$, VOL: Ejaculate volume $(\mathrm{ml})$, TS: Total sperms $\left(10^{9} /\right.$ ejaculate), IM: Initial motility (\%), PTM: Post thaw motility (\%), TNSDP: Theoretical number of semen doses.

\section{Figures}

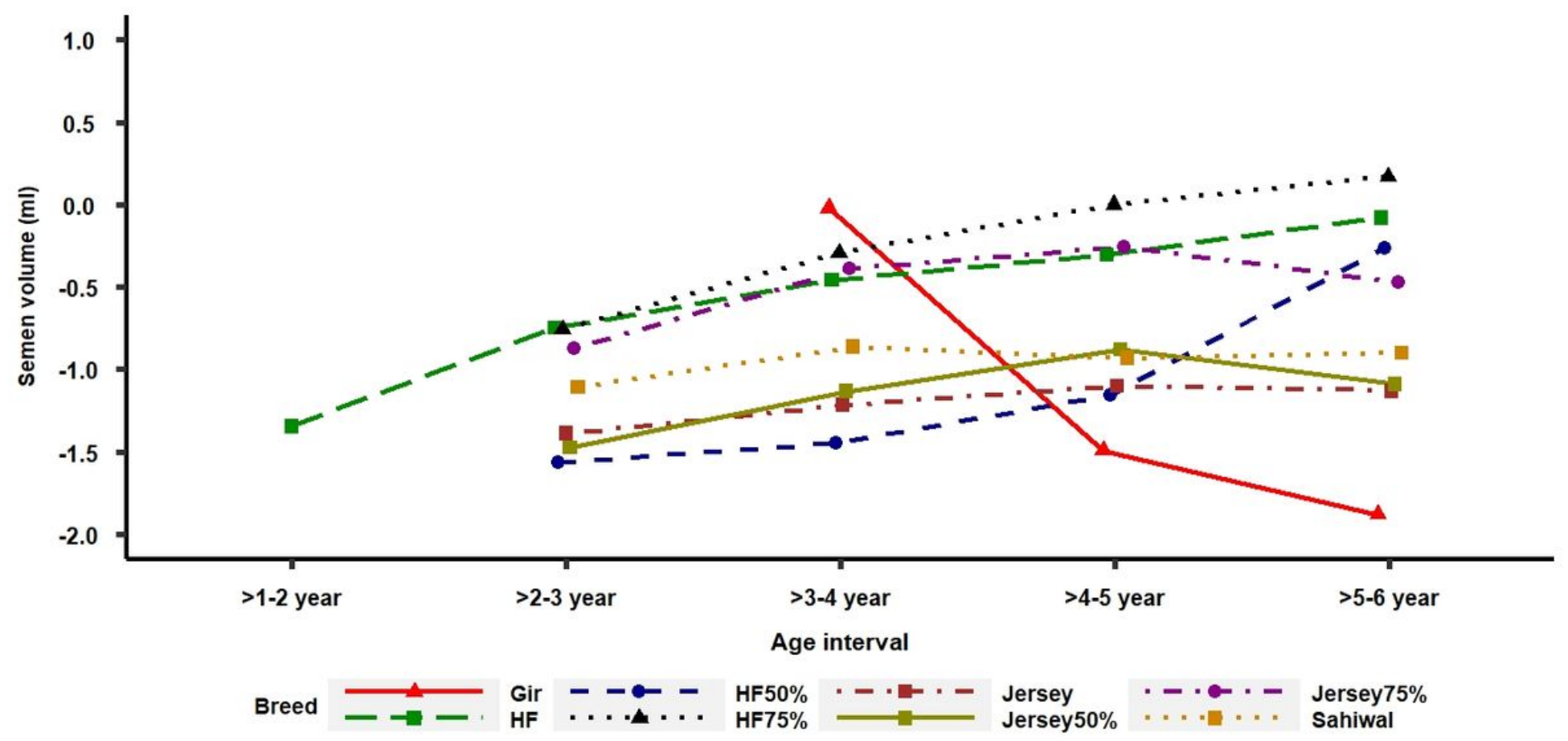

Figure 1

Effect of age at semen collection on ejaculate volume

(Subtitle: 0 = reference solution as HF $75 \% \times$ age ( $>4$ to 5 years)) 


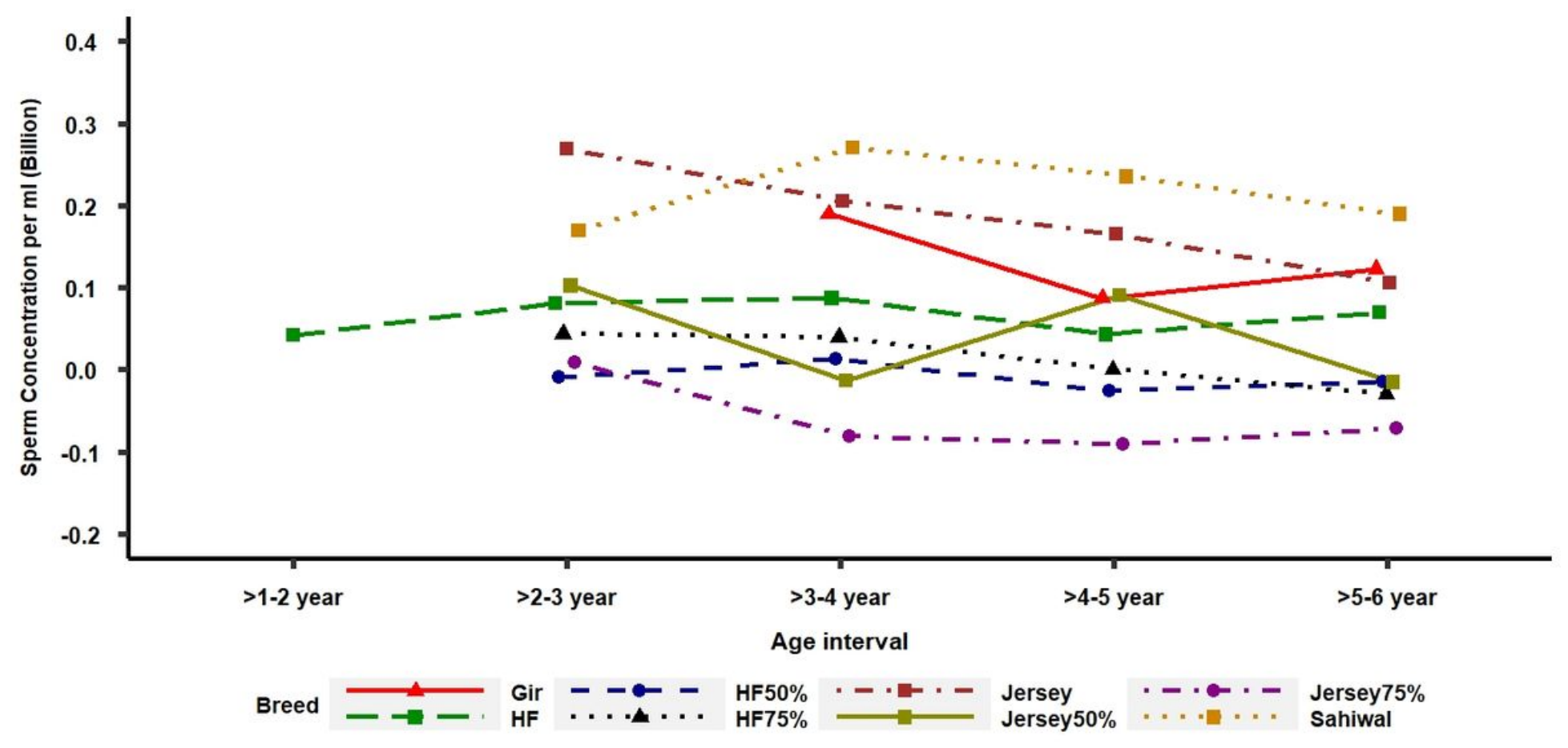

Figure 2

Effect of age at semen collection on sperm concentration

(Subtitle: $0=$ reference solution as HF $75 \% \times$ age $(>4$ to 5 years $)$ )

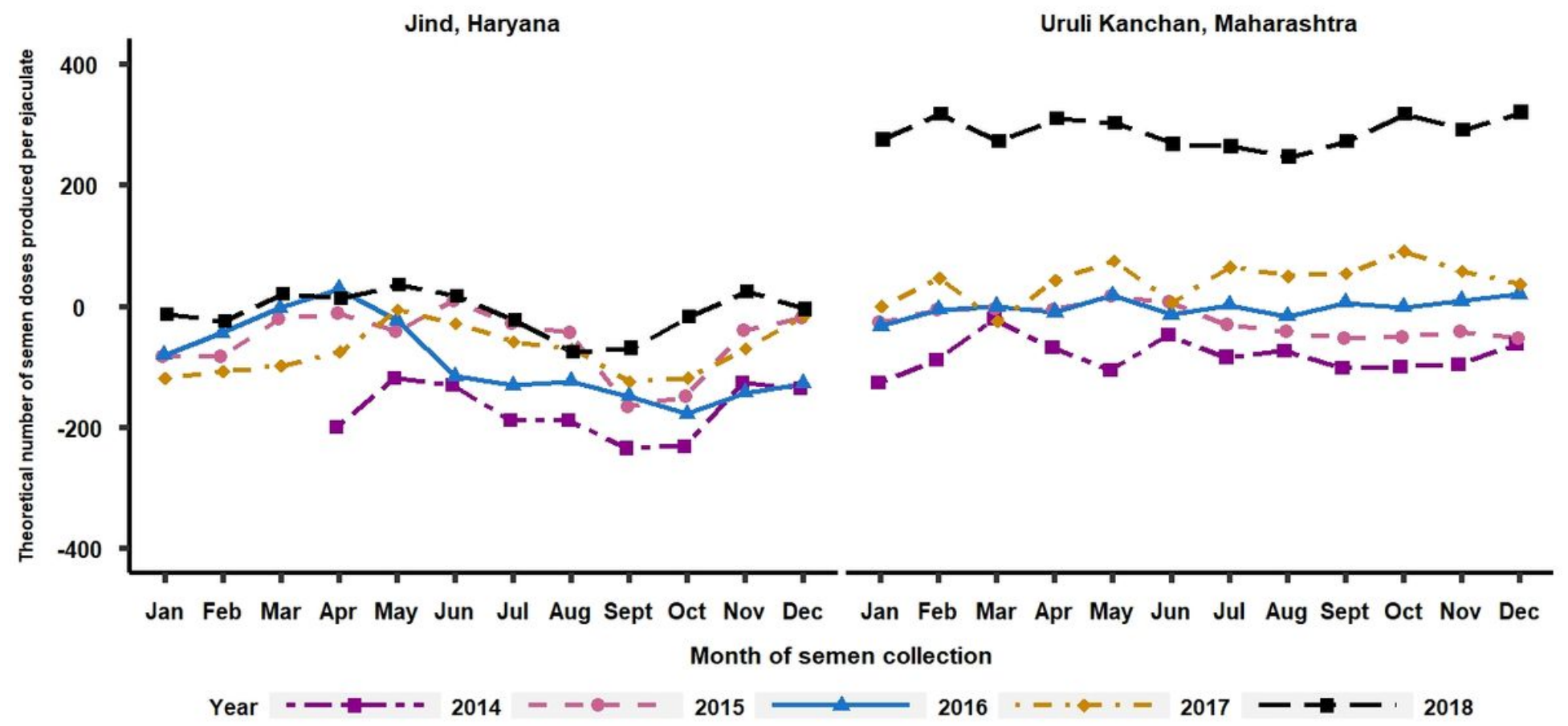

Figure 3

Effect of the month of semen collection on theoretical number semen doses over the year 
(Subtitle: 0 = reference solution as 2015 year $\times$ February month; for clarity, only 5 years are reported)

\section{Supplementary Files}

This is a list of supplementary files associated with this preprint. Click to download.

- Supplemetaryfile.docx 